\title{
A abertura da consulta. O fim está no princípio.
}

José Mendes Nunes*

\section{RESUMO}

O desenvolvimento tecnológico relacionado com a medicina levou à desvalorização da relação médico-doente em favor da relação médico-tecnologia. A consulta é um procedimento de diagnóstico e terapêutico de elevada complexidade técnica e o seu êxito depende da qualidade da relação médico-doente nela desenvolvida. Por outro lado, se, na relação médico-tecnologia, a competência está no saber fazer e quando fazer, na relação médico-doente, para além desta competência, é necessário saber ser e quando ser. Estas duas ordens de competências têm de ser constantes ao longo de todas as fases; no entanto, a observação da prática mostra que na fase de abertura existe alguma atenuação no grau de empenho do clínico, que se repercute nas fases subsequentes da consulta com impacto no resultado global. O presente trabalho tem por objectivos descrever argumentos demonstrativos da necessidade de maior investimento na fase de abertura, e apresentar algumas técnicas que aumentam a probabilidade de o doente construir primeiras impressões positivas e favoráveis ao estabelecimento de uma relação terapêutica efectiva.

\section{INTRODUÇÃO}

A Uma quantidade considerável de estudos demonstra uma associação entre a qualidade e as características da consulta com os resultados clínicos. ${ }^{1-5}$ Este efeito é mediado pelo estabelecimento de uma relação terapêutica efectiva que tem, na sua base, uma comunicação funcional entre médico e doente e a existência de clima terapêutico propiciador de uma atitude de entrega ao plano terapêutico por parte do doente.

Vários autores têm descrito a consulta como uma sucessão de fases, cada uma com tarefas específicas. ${ }^{6-9}$ Alguns autores chamam a atenção para a importância da fase de abertura. ${ }^{10,11}$ No entanto, na prática, considera-se uma fase de mero ritual que dispensa quaisquer cuidados especiais, por se tratar de uma fase em que não se aborda o que realmente interessa - o problema do doente.

A consulta é um encontro entre uma confiança e uma consciência. ${ }^{12}$ A confiança do doente no médico, na fiabilidade da sua prática, seguro de que actua no seu melhor interesse, que o compreende e se sente confirmado na sua individualidade. O médico possui um conhecimento cuja aplicação está dependente de interferências cognitivas, afectivas, emocionais e culturais,

*Chefe de Serviço de Clínica Geral, USF São Julião, Centro de Saúde de Oeiras. Assistente Convidado da Cadeira de Medicina Geral e Familiar, da Faculdade de Ciências Médicas, da Universidade Nova de Lisboa. para além do poder que lhe é investido pelo doente, sendo fulcral ter consciência destes factos de modo a aplicar o seu conhecimento técnico segundo a ética e as regras da sua profissão e o melhor estado da arte. Os acontecimentos e o contexto da fase inicial da consulta são determinantes para a construção da confiança do doente, componente imprescindível para o estabelecimento de uma relação terapêutica. O médico deve possuir perícias comunicacionais e criar condições adequadas, que lhe permitam construir a confiança do doente e eliciar as suas preferências, as quais têm elevada probabilidade de serem afectadas pelas suas experiências prévias com o médico ou com outros profissionais. ${ }^{13} \mathrm{O}$ presente artigo visa fundamentar a importância da fase de abertura da consulta e, deste modo, contribuir para que os profissionais a assumam como acto técnico cuja qualidade de desempenho tem grande impacto no sucesso terapêutico da consulta.

\section{A CONSULTA COMO CADEIA DE REACÇÕES}

A consulta pode ser vista como a sequência de reacções químicas que, no seu conjunto, fazem lembrar uma cadeia metabólica. Numa cadeia metabólica, no início, temos duas substâncias, os substratos, que são sujeitos a modificações sucessivas em cada uma das reacções que compõem essa cadeia metabólica, de tal modo que, no final, temos duas substâncias diferentes das iniciais, a que chamamos de produtos finais. Em todas as cadeias 
metabólicas existe uma reacção, energeticamente exigente, que limita a velocidade de produção. Esta reacção limitadora está sempre localizada numa fase inicial da respectiva cadeia, geralmente após a reacção inicial de activação dos substratos.

À semelhança de uma cadeia metabólica, no início da consulta, temos dois substratos: o doente e o médico. Estes substratos vão sofrendo transformações sucessivas ao longo das diferentes fases (pré-consulta $>$ abertura $>$ exploração $>$ resolução $>$ encerramento) da consulta de modo a, no final, resultarem dois produtos: médico transformado e doente transformado. Também, à semelhança do que acontece na cadeia metabólica, a fase fortemente limitadora da velocidade de transformação ou qualidade (leia-se o êxito da consulta) dos produtos finais, está localizada no início da cadeia reactiva da consulta, a fase de abertura, que sucede à fase de activação dos substratos, a fase de preparação. Portanto, a fase de abertura é fundamental para o estabelecimento da relação terapêutica; contudo, se fizermos uma retrospectiva das consultas que realizámos ou vimos realizar, constatamos que é uma das fases mais negligenciadas.

\section{O MÉDICO COMO FÁRMACO}

A qualidade de qualquer relação depende muito dos intervenientes cujas características positivas podem ser potenciadas ou anuladas pelo contexto, as circunstâncias ou o ambiente em que a mesma se desenrola. Para Michael Balint, ${ }^{14}$ o fármaco «médico» é a substância mais prescrita em Clínica Geral. A aceitação deste princípio é fundamental para a assumpção subsequente do valor terapêutico da relação médico-doente. Assim, as potencialidades terapêuticas do fármaco médico podem ser anuladas ou potenciadas pelo ambiente envolvente da relação. Neste sentido, pode-se dizer que o médico não é verdadeiramente um fármaco mas antes um pró-farmaco que, para exercer o seu efeito terapêutico, exige um processo de activação. Com efeito, o médico não exerce o seu efeito terapêutico pelo simples facto de se cruzar com o doente. Para adquirir esse potencial terapêutico, necessita que algo mais aconteça, qualquer acto que $o$ active e faça expressar as suas qualidades terapêuticas. O médico, para ser activado e transformado em substância activa, precisa de uma reacção (verdadeiramente uma transacção) com o doen- te que o activa. Esta activação do médico exige, em simultâneo, modificações no doente que se traduzem pelo reconhecimento do poder terapêutico daquele. $\mathrm{Na}$ verdade, o poder terapêutico (como qualquer poder real) não está no médico mas sim no doente que pode ou não investir ou atribuir esse poder ao médico. Se prosseguirmos nesta metáfora do médico como fármaco, a fase de abertura da consulta é o equivalente ao fenómeno de primeira passagem da farmacologia clínica. Um fármaco, na sua primeira passagem pelo território hepático, pode ser activado ou metabolizado, adquirindo ou perdendo o potencial terapêutico, respectivamente. À semelhança do «efeito de primeira passagem» também o potencial terapêutico do médico pode ser activado ou anulado na fase de abertura da consulta quando se estabelece o contacto com o doente. Frequentemente existem factores e acontecimentos que favorecem esta inactivação. Nestas condições, não é forçoso que o sucesso da consulta fique irremediavelmente perdido mas vai ser preciso maior «dose» do fármaco, isto é, mais esforço do médico e mais tempo, esse recurso tão escasso em Clínica Geral.

\section{A PREPARAÇÃO DA CONSULTA.}

Precedendo a fase de abertura está a fase preparatória ou de pré-abertura da consulta definida como o tempo em que o médico já está dedicado à consulta contudo ainda não está em contacto directo com o doente. É uma fase também determinante para o sucesso do encontro; porém, ainda não se iniciou propriamente um processo transaccional. Contudo, nesta fase, devem ser realizadas duas tarefas fundamentais para a consulta: uma relacionada com o doente que se segue, o planeamento da consulta com a ponderação do que está pendente e precisa de ser tratado na presente consulta e o reconhecimento do sujeito que se espera receber; a outra, relacionada com o médico, que deve avaliar quais são as suas forças e as suas fraquezas para enfrentar o encontro que se vai seguir. Esta tarefa inclui a tomada de consciência das emoções que sente e evitar que as mesmas contaminem a consulta, isto é, proceder «à descontaminação emocional». Enquanto o médico executa estas tarefas, o doente aguarda a sua chamada preparando o modo como vai apresentar a narrativa das suas queixas. Faz um varrimento das suas memórias recordando os discursos que teve com os familiares, ami- 
gos e consigo próprio acerca do seu sofrimento. Simultaneamente, revê a forma como se relaciona com o médico, ou, se não o conhece, imagina como pode ser recorrendo à memória de interacções anteriores com outros profissionais ou estereótipos construídos com base no que ouviu dizer ou viu acontecer. Para a construção destes esquemas mentais muito contribuíram as suas experiências prévias, a informação dos entes mais próximos e os meios de comunicação social.

\section{CONDIÇÕES FÍSICAS PARA A CONSULTA}

Os serviços de saúde, hospitalares e ambulatórios, desvalorizam e desprezam a generalidade dos espaços físicos onde se desenrolam os actos terapêuticos. De todos os serviços, onde se observa algum cuidado com a qualidade ambiental são os blocos operatórios e nos serviços onde há um elevado risco de infecciosidade. Mesmo assim, as preocupações ambientais limitam-se a garantir um ambiente biologicamente asséptico, porque os outros componentes ambientais, como agradabilidade, conforto e estética são negligenciados, chegando mesmo a descurar a manutenção regular da temperatura.

A privacidade dos locais de consulta é, constantemente, desrespeitada verificando-se uma permanente devassa do espaço terapêutico por profissionais, utentes e até delegados de informação médica. A maioria comporta-se como se a consulta e o seu local fossem aspectos que não merecem qualquer cuidado, assumindo-se que têm uma função meramente circunstancial sem qualquer impacto na qualidade dos cuidados prestados. Comportam-se como se a qualidade da cama onde se dorme não tivesse qualquer importância para a qualidade do sono.

Imagine que convidou alguém para ir a sua casa. Alguém que preza e tem muito prazer em receber e, para além disso, deseja impressioná-lo positivamente.Vários dias antes começa a preparar essa visita. Verifica se a casa está limpa, arrumada, planeia comprar flores, escolhe a toalha que vai pôr na mesa, a loiça que vai utilizar, etc. Faz tudo pensando na pessoa que vai receber. Executa tudo isto de modo consciente e premeditado, para que a pessoa se sinta o melhor possível e para que a relação entre os dois se consolide e, sobretudo, preocupa-se em dar uma imagem positiva de si e dos seus.

Agora faça uma retrospectiva dos cenários de con- sulta que frequentemente presenciou. Mobiliário degradado, papéis espalhados por tudo quanto é sítio. $\mathrm{Na}$ secretária, não se descortina qualquer espaço livre e há literaturas de propaganda farmacêutica por todo lado. Nos gabinetes com computador, identifica-se um monitor que emerge dum mar de literaturas e outros papéis, qual iceberg emergente do oceano. O rato do computador adivinha-se perdido entre as literaturas e os montes de impressos do SNS. As faces laterais, e apostava que mesmo o tampo, da secretária e da CPU estão cravejadas de autocolantes, também eles publicitando produtos farmacêuticos. O pó está omnipresente e bem visível assumindo-se que, perante tal caos, nem vale a pena tentar limpar. A cadeira para o doente está do lado oposto ao lugar do médico, geralmente mais baixa que a daquele. No bordo da secretária, mais próximo do doente, encontra-se um «muro» formado pelos mais diversos objectos: o monitor do computador; copo com diversas canetas, o copo e as canetas são veículos de publicidade a produtos farmacêuticos; um calendário em forma de cabana, com o mês virado para o médico e, do outro lado, mais um ou dois anúncios a produtos farmacêuticos, ali, bem nos olhos do doente; segue-se outro veículo de publicidade da indústria, um porta-clips, alguns destes têm mesmo mensagens iconográficas de produtos farmacêuticos; e, finalmente, um esfigmomanómetro e um monte de processos clínicos que aguardam arquivamento. Tudo em fila, formando uma barreira física entre os dois interlocutores que tentam comunicar por cima dela, como se estivessem a jogar à batalha naval. As paredes dizem muito mais da indústria farmacêutica que dos profissionais ou dos serviços.

Os dois ambientes, que acabamos de descrever, são muito diferentes, mas parece que todos estamos de acordo que os princípios e as atitudes subjacentes aos dois encontros deviam ser iguais. Então por que não o são? Não sei, nem se calhar devo dar respostas sem ofender alguém mas, já vi médicos que retiram premeditadamente cadeiras dos gabinetes para que os doentes não se demorem. Certamente que esta é uma estratégia eficaz para aquele objectivo, o que demonstra bem como o clínico sabe o quão importante é o ambiente da consulta para o estabelecimento da relação. Em termos hiperbólicos: não há ambiente, não há relação.

Warren, citado por Rapport et al., introduziu o conceito de «estética organizacional» para nomear a expe- 
riência estética do local de trabalho e o seu impacto no desempenho profissional. O espaço da consulta é o palco onde o médico e o doente representam os seus papéis atribuídos pela sociedade. $\mathrm{O}$ estudo de Frances Rapport et al. ${ }^{15}$ revela as várias perspectivas que os clínicos gerais têm sobre o espaço da consulta: seguro, pessoal, icónico, efémero, restritivo, comunicativo, de trocas e geográfico. O espaço da consulta deve traduzir a vontade de contribuir para a construção da relação de confiança, propiciar a boa prática pelo profissional, facilitar o doente a revelar-se tal como é e expressar as suas ideias. O cenário físico do palco terapêutico deve inspirar o médico e libertar o doente.

Concluímos que, em todos os encontros, o aspecto ambiental, tal como as características pessoais, são importantes determinantes da relação. ${ }^{16}$ Veja-se o quanto as organizações comerciais, os bancos, a maioria das consultas na privada, investem na qualidade das instalações.

Chega a parecer um milagre a consulta ter um impacto positivo, se à má qualidade das instalações acrescentarmos o barulho à porta do gabinete, o telefone que toca, as constantes e intempestivas entradas no gabinete pelos mais diversos profissionais e utentes, enquanto o doente continua ali, sentado, a observar todo aquele caos, interrogando-se se, por magia, acabou de adquirir propriedades de invisibilidade.

Um estudo de grandes dimensões, realizado no Reino Unido, mostrou que a melhoria das condições ambientais se associa à percepção, pelo utente, de melhor comunicação médico-paciente, redução da ansiedade e aumento da satisfação do doente e dos profissionais. ${ }^{17}$ Apesar dos factores ambientais serem fundamentais para o bem-estar e segurança dos pacientes e dos profissionais, tradicionalmente não têm sido considerados prioritários pelas autoridades. ${ }^{18}$

Balint e Balint ${ }^{12}$ falavam do «setting ${ }^{a}$ terapêutico» não só referindo-se às condições materiais do encontro, como também à «soma das condições relativamente constantes» criadas pela maneira individual do médico praticar medicina. Condições que o doente pode utilizar e que deve aceitar: «a atmosfera terapêutica é oferecida ao doente para que ele se sirva dela na tentativa

a. O termo «setting» é muito utilizado no teatro no sentido de colocar em cena. Traduz o sentido do ambiente terapêutico e que Balint definia como a «atmosfera terapêutica oferecida ao doente». Os franceses chamam-lhe «climat thérapeutique». de obter ajuda profissional qualificada». ${ }^{12}$

O cuidado que a equipa cirúrgica tem com o bloco operatório, o setting terapêutico da cirurgia, reconhecidamente um determinante para o êxito da cirurgia, deve ser transposto, de igual modo, e devidamente adaptado, para o gabinete de consulta $\mathrm{o}$ «setting» terapêutico da Medicina Familiar. Embora não seja a terapêutica, o gabinete de consulta é, contudo, um importante determinante para o sucesso da relação médico-doente.

Em resumo, existe um certo número de condições físicas básicas fundamentais para o êxito da entrevista clínica. Estas condições são tão básicas que geralmente são consideradas como adquiridas. Funcionam como mensagens que predispõem os intervenientes para aceitar ou recusar o que lhes é proposto nesse contexto. São condições físicas básicas para a consulta:

- Privacidade;

- Ausência de motivos de distracção ou interrupções;

- Conforto;

- Agradabilidade;

- Pormenores proxémicos, como facilidade dos intervenientes se verem de olhos nos olhos e com a distância adequada (nem tão intensa que intimide, nem tão ausente que desconfirme o doente). ${ }^{19}$

\section{A ABERTURA DA CONSULTA}

Para Steiner Kvale, ${ }^{20}$ "os primeiros minutos de uma entrevista são decisivos». O doente deseja ter uma impressão do médico antes de iniciar uma conversa livre em que expõe as suas experiências e sentimentos a um estranho. O bom contacto estabelece-se através de uma escuta activa, com o médico mostrando interesse, compreensão e respeito pelo que o doente diz, através de um comportamento e atitude que podemos definir como «escutar com o corpo todo». Bruno Bettelheim, ${ }^{21}$ a propósito da importância do primeiro contacto num processo psicoterapêutico, dizia «o fim está no princípio», querendo salientar que muito do sucesso final de uma terapia estava nas condições iniciais do primeiro contacto. Se considerarmos que na consulta se podem passar muitas das fases que ocorrem ao longo de um processo psicoterapêutico, vemos um indício da grande importância de um forte investimento na fase inicial da consulta. A sabedoria popular também valoriza a importância dos primeiros momentos de um contac- 
to quando diz que «não há segunda oportunidade para as primeiras impressões».

$\mathrm{Na}$ fase de abertura podemos considerar dois tempos, o intróito e o tempo de fuga ou tempo de monólogo, delimitados por um separador a que designamos de gambito. O intróito corresponde ao primeiro tempo em que se verificam transacções que nada têm a ver com os motivos da consulta. O doente preparou o discurso para apresentar as suas queixas mas, quando encontra o médico, surgem reacções desencadeadas pelas sensações e automatismos que o encontro, face a face, lhe despertou. Por vezes, resumem-se a rituais de saudação como «bom dia, como está?» a que o doente de forma automática pode responder com um:

- Tudo bem, obrigado!

Para depois dizer:

- Tenho andado com umas dores nas costas que não me deixam fazer seja o que for.

A escolha da pergunta «como está?» é mais própria de consultas de seguimento enquanto que a questão «em que lhe posso ser útil» ou «o que o trouxe hoje à consulta» é mais própria de consultas de iniciativa do doente. Durante o intróito, os interlocutores tomam consciência mútua e abrem canais de comunicação entre os dois. Nele, o doente toma conhecimento e sente que o médico o escuta e está receptivo às suas queixas enquanto o médico constata que o doente está na consulta de corpo inteiro, disposto a ouvir e atento para tudo o que o clínico diz e faz. Enfim, cumpre-se a função fática da comunicação. O erro mais frequente é o médico emitir precocemente sinal para o doente falar das suas queixas sem primeiro se assegurar que, realmente, ele está presente no seu todo. Quantas vezes lhe coloca logo a questão «o que o traz cá hoje», sem que o doente tenha tido a oportunidade de se sentar. Este tempo é tanto mais importante quanto mais recente é o início de contactos entre médico e doente. No doente que vem pela primeira vez à consulta, este tempo é vital para estabelecer um contacto que confirma o próprio doente, condição vital para criar um clima terapêutico. O tempo de socialização está fortemente associado à satisfação do doente com a consulta, ${ }^{22}$ mesmo quando esse tempo se reduz a 5 segundos..$^{23}$ Dentro deste tempo, inclui-se a auto-apresentação do médico que sendo fundamental para estabelecer qualquer relação é, para além disso, um acto de boa educação e uma de- monstração efectiva do respeito que o médico tem pelo doente. A escolha da forma como o médico chama o doente é um aspecto a ser cuidado. Geralmente somos muito sensíveis ao modo como nos tratam mas desvalorizamos consideravelmente como o fazemos aos doentes. Brian McKinstry ${ }^{24}$ verificou que a maior parte dos doentes gosta de ser chamada pelo primeiro nome, no entanto, $16 \%$ mostraram-se desagradados por esta forma de tratamento informal. A frequência dos desagradados pela forma mais informal era maior nos idosos e na classe social I de Graffar. O mesmo autor chama a atenção para o facto de se usar o primeiro nome do doente, enquanto se usa o apelido do médico, pode ser uma expressão da assimetria da relação, vincadamente paternalista, diminuindo o sentido de autonomia do doente e debilitando-o na assumpção das suas escolhas, podendo reduzir a efectividade do terapeuta. Embora estas conclusões devam ser relativizadas ao respectivo contexto cultural, neste caso a Escócia, o estudo tem o mérito de chamar a atenção para aspectos que, sendo considerados menores para a prática médica, não deixam de ser importantes para quem quer utilizar todos os recursos disponíveis que possam contribuir para o sucesso terapêutico. A estes aspectos comunicacionais, aparentemente sem importância para o acto médico em si, mas que o podem afectar negativa ou positivamente, chamo de «amenidades comunicacionais» e devem ser estudados nas populações em que se trabalha, dado que os resultados obtidos noutras sociedades só por coincidência podem ser transferíveis.

\section{AS PRIMEIRAS IMPRESSÕES}

O investimento na fase de abertura encontra justificação em muitos dados da psicologia. De acordo com Daryl Bem, ${ }^{25}$ a primeira informação que recebemos tem grande impacto nas informações subsequentes, designando este fenómeno de «efeito de primazia». Este efeito é demonstrado por um número considerável de experiências com cenários hipotéticos e reais. As primeiras impressões formam-se nos primeiros segundos do contacto, de modo inconsciente, e pertencem ao campo da intuição. ${ }^{26}$ As primeiras impressões são fortemente determinadas pelos esquemas mentais e contribuem grandemente para a sua preservação. As primeiras impressões, sobretudo se estiverem de acordo com os esquemas mentais, afectam as percepções e a memó- 
ria, criando verdadeira cegueira para dados que eventualmente apontem para a negação daquelas primeiras impressões. A este fenómeno, Daryl Bem chama de «efeito de perseverança». Como consequência comportam-se como profecias auto-realizáveis, até porque, na maioria das vezes, as pessoas acreditam que apresentam os mesmos traços comportamentais em todas as situações e desvalorizam o papel do contexto como determinante do comportamento, apesar de, já no início do século XX, Ortega y Gasset ter afirmado «Eu sou: eu e a minha circunstância». Portanto, à prematuridade $\mathrm{e}$ rapidez com que definimos ou julgamos os nossos interlocutores, junta-se a descontextualização dos comportamentos observados construindo o que a psicologia designa de «erro fundamental de atribuição». Nestas circunstâncias, o ser humano não precisa de conhecer o outro para acreditar que o conhece. ${ }^{27}$ No entanto, o contexto, por exemplo, a tristeza, afecta significativamente a acuidade da primeira impressão. ${ }^{28}$

Claro que este fenómeno funciona nos dois interlocutores, médico e doente. Assim, como técnicos, a nossa preocupação deve dirigir-se para o impacto do comportamento do profissional nas percepções do doente e tomar consciência das impressões instantâneas que o doente induziu no médico. No último caso, essa consciência permite avaliar o significado das impressões sobre o doente, formadas no acto do contacto, contextualizá-las e tentar ficar atento e receptivo a novos indícios que contrariem o efeito de primazia. Trata-se de avaliar as emoções que o doente gera em nós, i.e. a vertente farmacocinética do fármaco médico que sai do objectivo deste texto. Aqui, pretendo mais salientar o que o profissional pode fazer, ou não deve fazer, para melhorar as probabilidades de o doente construir as suas primeiras impressões favoráveis ao estabelecimento de uma relação terapêutica tão efectiva quanto possível. Com este objectivo, em primeiro lugar, há que procurar sentir-se bem no papel que desempenha. $\mathrm{O}$ que para uns é fácil, para outros é muito difícil. Contudo, é animador saber que é sempre possível melhorar através da hetero e auto-critica constantes, auto-consciência dos comportamentos e prática persistente com o genuíno interesse em querer fazer melhor. Em segundo lugar, sorrir e falar claro, o que para alguns é natural mas para outros não é fácil. De qualquer modo, a recomendação para o conseguir continua a ser auto- -consciência, auto-critica e prática aperfeiçoadora. Sorrir, para além de contribuir para uma impressão positiva no interlocutor, tem a vantagem de criar, no próprio, uma emoção positiva de bem-estar. «Sorria e o Mundo sorrirá também». ${ }^{29}$ Receber o doente com cordialidade, ou seja, expressar um conjunto de gestos e atitudes que dão a ideia de reconhecimento e de respeito pelo outro, como por exemplo, chamar o doente pelo nome, receber à porta, oferecer lugar para se sentar e local para colocar pertences, ajudar a sentar quando adequado, olhar para o doente e cumprimentar com o modo que o doente parece desejar. A decisão sobre o modo como cumprimentar o doente é intuitiva, embora seja conhecido que o mais frequente é o aperto de mão convicto sem ser excessivamente vigoroso. Outros factores que contribuem para uma boa impressão são a pontualidade, ser natural, não simulado, ou seja, transmitir uma imagem de coerência, em que "todo o corpo» diz a mesma coisa. A auto-apresentação é um procedimento muito pouco habitual nos nossos serviços de saúde mas que, para além de ser uma regra básica de boa educação, contribui fortemente para o impacto positivo no outro. Cuide da sua imagem tendo em atenção não ferir susceptibilidades, embora preservando o seu estilo e individualidade, a forma como se veste deve expressar respeito pelo outro. Seja positivo, acredite na pessoa que está à sua frente e veja em cada encontro a oportunidade de descobrir novo mundo. Tente, sempre, iniciar o contacto com uma palavra de reconhecimento positivo do outro, que não só o confirma enquanto ser humano mas também contribui para a valorização da auto-estima. Finalmente, relembra-se a importância de construir o intróito, considerando um momento de transacções de enorme importância para abrir os canais de comunicação vitais ao estabelecimento de uma efectiva relação terapêutica.

\section{O TEMPO DE FUGA}

Após o tempo de fuga, uma das tarefas fundamentais é o estabelecimento da agenda da consulta. Este cuidado minimiza a probabilidade do surgimento tardio de novos motivos de consulta. O que não só é dispendioso em termos de tempo como perturba fortemente o médico, com profundo impacto no seu desempenho. Assim, muitos autores defendem a não interrupção do doente no tempo de fuga e a utilização de facilitações, ${ }^{\mathrm{b}}$ 
QUADRO I. Comportamentos e atitudes que induzem boa impressão

- Sentir-se bem no papel que desempenha

- Ser pontual

- Sorrir

- Falar claro

- Ser positivo (acreditar em si e no outro)

- Auto-apresentar-se

- Cumprimentar

- Construir o intróito

- Ser cordial

- Olhar nos olhos

em vez da imediata focagem na caracterização detalhada dos primeiros sintomas apresentados. Este modo de proceder geralmente não leva mais de 2 ou 3 minutos e permite poupar tempo e, sobretudo, executar um trabalho de maior qualidade. ${ }^{30,31}$ Walter et al., ${ }^{11}$ salientam que um erro frequente é a interrupção do doente quando começa a narrar a sua história. À pergunta aberta, que convida o doente a falar sobre os seus motivos de consulta, deve suceder um comportamento de escuta

b. Entende-se por facilitações toda a mensagem verbal e ou não verbal que incentive a narrativa. Por exemplo, hum, hum! Ou, simplesmente, o acenar de cabeça.

\section{QUADRO II. Tempos médios de fuga}

\begin{tabular}{l|l|l|c}
\multicolumn{1}{c|}{ Autores } & \multicolumn{1}{c|}{ País } & \multicolumn{1}{c|}{ Contexto } & $\begin{array}{c}\text { Tempo de fuga } \\
\text { (média em seg.) }\end{array}$ \\
\hline $\begin{array}{l}\text { Blau JN (1989) } \\
\text { Svab I, Katic M } \\
\text { e Cuk C (1993) }\end{array}$ & Reino Unido & Neurologia & 100,0 \\
\hline $\begin{array}{l}\text { Svab I, Katic M } \\
\text { e Cuk C (1993) }\end{array}$ & Croácia & Clínica Geral & 21,9 \\
\hline $\begin{array}{l}\text { Marvel MK } \\
(1999)^{34}\end{array}$ & EUA & Clínica Geral & 23,0 \\
\hline $\begin{array}{l}\text { Langewitz W } \\
\text { e outros (2002) }\end{array}$ & Suiça & Medicina Interna & 92,0 \\
$\begin{array}{l}\text { Rabinowitz I } \\
\text { e outros (2004) }\end{array}$ & Israel & Clínica Geral & 26,0 \\
$\begin{array}{l}\text { Rhoades DR e } \\
\text { outros (2001) }\end{array}$ & EUA & $\begin{array}{l}\text { Internos de } \\
\text { Medicina Familiar }\end{array}$ & 12,0 \\
\hline
\end{tabular}

activa por parte do médico.

No estudo de Bekman e Frankel ${ }^{31}$ realizado em cuidados primários, os médicos interrompiam os doentes, em média, ao fim de 18 segundos. A desculpa frequente para que os médicos assim procedam é que este monólogo consome tempo e atrasa as consultas.

Autores, de diferentes culturas, têm demonstrado que, quando o doente não é interrompido, o tempo médio de fuga não ultrapassa os 30 segundos. Os valores apresentados no Quadro II são tempos médios, contudo, em todos há uma concentração de valores para a esquerda da curva, com alguns (poucos) valores muito afastados para a direita da média que fazem com que este indicador seja, por si só, muito pouco esclarecedor. Por exemplo, no estudo de Langewitz, ${ }^{35}$ que envolveu a análise de 406 consultas, apenas 7 doentes ultrapassaram os 5 minutos enquanto que $78 \%$ do total não ultrapassou os 2 minutos.

Esta distribuição de valores também explica, pelo menos em parte, o receio que os clínicos têm em deixarem os clientes exporem livremente as suas queixas. É que, obedecendo à tendência psicológica de «generalizar o que é mau», as poucas experiências em que surgem doentes verborreicos levam a uma hiper-representação mental deste tipo de doentes, por parte do médico, e a ficar com a ideia de que todos os doentes falam muito, pelo que tem de lhes conter o discurso.

No entanto, os estudos experimentais mostram o contrário. Rabinowitz et al. ${ }^{36}$ compararam o tempo de monólogo, em dois dias consecutivos, num grupo de clínicos gerais, pedindo, no segundo dia, para não interromperem o doente durante o ponto de fuga com novas questões. O tempo de monólogo durou 26 segundos, no primeiro dia, e 28 segundos, no segundo, e foi interrompido com nova questão em $68 \%$ e $35 \%$ das consultas no primeiro e segundo dias, respectivamente. Contudo, a duração média da consulta reduziu de 10,5 minutos, no primeiro dia, para 9 minutos no segundo. Donde se conclui que a interrupção precoce do tempo de fuga tem mais a ver com a ansiedade do clínico que com o maior dispêndio de tempo.

\section{CONCLUSÃO}

A consulta é um dos mais nobres meios de prestar cuidados de saúde e exige grande tec- 
nicismo e constante concentração ao longo de todas as fases. No entanto, na prática, nem todas as fases têm a mesma atenção, nomeadamente a preparação e a abertura. Acredita-se que o relativo desleixo destas fases seja determinado por se considerar que não se está a abordar concretamente o problema que trouxe o doente à consulta. Todavia, a evidência aponta que o empenho nestas fases é determinante para a qualidade da globalidade da consulta e tem impacto nos resultados.

O fenómeno das primeiras impressões está omnipresente em ambos os interlocutores. Neste sentido, o clínico deve estar consciente que as primeiras impressões que o doente lhe induz podem condicionar o seu raciocínio e comportamento com os consequentes resultados desastrosos para ambos, se não forem conscientemente relativizadas através da auto-consciência, auto-conhecimento, auto-controlo e auto-critica. $\mathrm{O}$ doente vai igualmente e inexoravelmente ter as suas primeiras impressões acerca do médico, com grande probabilidade de elas se fixarem por muito tempo, dado que ele não tem a preparação técnica do profissional. Contudo, o clínico deve ter presente que pode criar condições que aumentem a probabilidade de provocar boa impressão no doente, importante para criar uma efectiva relação terapêutica. Para este efeito, o clínico deve procurar condições pessoais que não contaminem aquele setting terapêutico com emoções que lhe são estranhas e toda a equipa é responsável por criar condições ambientais que propiciem condições facilitadoras do maior êxito do encontro. A cooperação com o doente no estabelecimento de uma agenda comum para a consulta é uma tarefa a cumprir na abertura da consulta. Sendo vital para a gestão mais eficiente do tempo, dá um sinal forte ao doente da importância que o médico atribui ao seu problema, confirma-o como pessoa única e mostra a pretensão de fazer uma consulta com o doente e não apenas para o doente.

O presente trabalho resulta da utilização de fontes de informação diversificadas, traduzindo o facto de a Medicina Geral e Familiar ser uma forma de praticar medicina por de mais humana para se aprender apenas com médicos.

\section{REFERÊNCIAS BIBLIOGRÁFICAS}

1. Henbest RJ, Fehrsen GS. Patient-centredness: is it applicable outside the West? Its measurement and effect on outcomes. Fam Pract 1992 Sep; 9 (3): 311-7.
2. Little P, Everitt H, Williamson I, Warner G, Moore M, Gould C, et al. Observational study of effect of patient centredness and positive approach on outcomes of general practice consultations. BMJ 2001 Oct 20; 323 (7318): 908-11.

3. Bertakis KD, Roter D, Putnam SM. The relationship of physician medical interview style to patient satisfaction. J Fam Pract 1991; 32 (2):175-81.

4. Bartlett EE, Grayson M, Barker R, Levine DM, Golden A, Libber S. The effects of physician communications skills on patient satisfaction; recall, and adherence. J Chron Dis 1984; 37 (9-10): 755-64.

5. Falvo D, Tippy P. Communicating information to patients: patient satisfaction and adherence as associated resident skill. J Fam Pract 1988 Jun; 26 (6): 643-7.

6. Pendleton D, SchofieldT, Tate P, Havelock P. A consulta: uma abordagem à aprendizagem e eEnsino.Porto: Departamento de Clínica Geral da Faculdade de Medicina do Porto; 1993.

7. Pendleton D, Schofield T, Tate P e Havelock P. The new consultation. Developing doctor-patient communication. Oxford: Oxford University Press; 2004.

8. Larsen JH, Risør O, Putnam S. P-R-A-C-T-I-C-A-L: a step-by-step model for conducting the consultation in general practice. Fam Pract 1997 Aug; 14 (4): 295-301.

9. Neighbour R. The inner consultation. How to develop an effective and intuitive consulting style. London: MTP Press Limited; 1991.

10. Lloyd M, Bor R. Communication skills for medicine. London: Churchill Livingstone; 1996.

11. Walter A, Bundy C, Dornan T. How should trainees be taught to open a clinical interview? Med Educ 2005 May; 39 (5): 492-6.

12. Balint $M$, Balint $E$. Techniques psychothérapeutiques en medicine. Paris: Éditions Payot; 2006.

13. Say RE, Thomson R. The importance of patient preferences in treatment decisions: challenges for doctors. BMJ 2003 Sep 6; 327 (7414): 542-5.

14. Balint M. The doctor, his patient and the illness. London: Churchill Livinstone; 1993.

15. Rapport F, Doel MA,Wainwrigth P. The doctor's tale: enacted workspace and the general practitioner. Forum Qualitative Sozialforschung/Forum: Qualitative Social Research 2007; 9(2). Disponível em: http://www.qualitative-research.net/index.php/fqs/article/view/406 [acedido em 30/04/2009].

16. Lussier MT, Richard C. Because one shoe doesn't fit all:A repertoire of doctor-patient relationships. Can Fam Phys 2008 Aug;54(8):1089-92, 1096-9.

17. Rice G, Ingram J, Mizan J. Enhancing a primary care environment: a case study of effects on patients and staff in a single general practice. $\mathrm{Br}$ J Gen Pract 2008 Jul; 58 (552): 465-70.

18. McSherry R, Pearce P. What Is Clinical Governance? In: Clinical Governance: a guide to implementation for healthcare professionals. Oxford: Blackwell Publishing; 2007. p. 16-43.

19. Billings JA, Stoeckle JD. The clinical encounter: a guide to the medical interview and case presentation. 2nd ed. St. Louis: Mosby; 1999.

20. Kvale S. Doing Interviews. London: Sage; 2007.

21. Bettelheim B, Rosenfeld A. Dans les chaussures d'un autre: la psychotérapie, art de l'évidence. Paris: Éditions Robert Laffont; 1995.

22. Gross DA, Zyzanski SJ, Borawski EA, Cebul RD, Stange KC. Patient satisfaction with time spent with their physician. J Fam Pract 1998; 47(2):133-7. 
23. Eide $H$, Graugaard $P$, Holgersen K, Finset A. Physician communication in different phases of a consultation at an oncology outpatient clinic related to patient satisfaction. Patient Educ Couns 2003 Nov; 51 (3): 259-66.

24. McKinstry B. Should general practitioners call patients by their first names? B M J 1990 Oct 6; 301: 795-6.

25. Bem D. Errors and biases in our perception of self and others. In:Aquém e Além do Cérebro. $4^{\circ}$ Simpósio da Fundação Bial. Porto: Fundação Bial; 2002. p. 49-72.

26. Ambady N, Bernieri FJ, Richeson JA. Toward a History of Social Behavior: Judgmental Accuracy from thin Slices of the Behavioral Stream. Adv Exp Soc Psychol 2000; 32: 201-71.

27. Gladwell M. The new-boy network: what do job interviews really tell us? The New Yorker 2000 May 5: 68-86.

28. Ambady N, Gray HM. On being sad and mistaken: mood effects on the accuracy of thin-slice judgements. J Pers Soc Psychol 2002 Oct; 83 (4): 947-61.

29. Gillett D. Smile, and the World Smiles With You. UAB Magazine. Disponível em: http://main.uab.edu/show.asp?durki=107013 [acedido em 30/04/2009).

30. White J, Levinson W, Roter D. "Oh, by the way..." the closing moments of the medical visit. J Gen Intern Med 1994 Jan; 9 (1): 24-8.
31. Beckman HB, Frankel RM. The effect of physician behavior on the collection of data. Ann Intern Med 1984 Nov; 101 (5): 692-6.

32. Blau JN. Time to let the patient speak. BMJ 1989 Jan 7; 298 (6665): 39.

33. Svab I, Katic M, Cuk C. El tiempo del paciente cuando habla sin interrupciones. Aten Primaria 1993 Mar 15; 11 (4): 175-7.

34. Marvel MK, Epstein RM, Flowers K, Beckman HB. Soliciting the patient's agenda: have we improved? JAMA 1999 Jan 20; 281 (3): 283-7.

35. Langewitz W, Denz M, Keller A, Kiss A, Rüttimann S, Wössmer B. Spontaneous talking time at start of consultation in outpatient clinic: cohort study. BMJ 2002 Sep 28; 325 (7366): 682-3.

36. Rabinowitz I, Luzzati R, Tamir A, Reis S. Length of patient's monologue, rate of completion, and relation to other components of the clinical encounter: observational intervention study in primary care. BMJ 2004 Feb 28; 328 (7438): 501-2.

37. Rhoades DR, McFarland KF, Finch WH, Johnson AO. Speaking and interruptions during primary care office visits. Fam Med 2001 Jul-Aug; 33 (7): 528-32.

\section{ENDEREÇO PARA CORRESPONDÊNCIA}

José Mendes Nunes

Pcta. Pero da Covilhã, $n^{\circ} 72-3^{\circ}$ DTO.

Junqueiro

2775 Carcavelos

\section{ABSTRACT}

The technological development related with medicine lead to the depreciation of the doctor-patient relationship in favour of the relationship doctor-technology. The consultation is a diagnosis and therapeutic procedure with high technical complexity and its success depends on the quality of the doctor-patient relationship developed. On the other hand, if in the relationship doctor-technology the competence is in the knowledge how to do and when to do, in the doctor-patient relationship, besides this competence, it is necessary to know how to be and when to be. These two orders of competences must be constant throughout all consultation's stages; however, the observation of practice shows that in the opening phase there is attenuation in the level of provider's commitment. This lower commitment affects the subsequent stages of consultation and has a negative impact on the overall result. The aims of this work are to describe arguments that point out to the importance of awareness and commitment in opening stage, and present some techniques designed to increase the probability of the patient building positive first impressions, which are precious to the establishment of an effective therapeutic relationship. 